Disclosure of Interests: : Benoit GILBERT: None declared, Kim Lauper: None declared, Delphine Courvoisier: None declared, Clementine Perrier Shareholder of: Share of Eli Lilly Company, Employee of: I am currently an employee of Eli Lilly Suisse SA, Rudiger Muller Consultant of: AbbVie, Nordic, Sandoz, Axel Finckh Grant/research support from: Pfizer: Unrestricted research grant, Eli-Lilly: Unrestricted research grant, Consultant of: Sanofi, AB2BIO, Abbvie, Pfizer, MSD, Speakers bureau: Sanofi, Pfizer, Roche, Thermo Fisher Scientific DOI: 10.1136/annrheumdis-2020-eular.1243

\section{THU0204 A SUBGROUP ANALYSIS OF LOW DISEASE ACTIVITY AND REMISSION FROM PHASE 3 STUDY OF FILGOTINIB IN PATIENTS WITH INADEQUATE RESPONSE TO BIOLOGIC DMARDS}

J. E. Gottenberg ${ }^{1}$, M. H. Buch ${ }^{2}$, R. Caporali ${ }^{3}$, G. C. Wright ${ }^{4}$, T. Takeuchi ${ }^{5}$, K. Kalunian ${ }^{6}$, A. Pechonkina ${ }^{7}$, Y. Guo ${ }^{7}$, S. Rao ${ }^{7}$, Y. $\operatorname{Tan}^{7}$, R. Besuyen ${ }^{8}$, M. C. Genovese ${ }^{9}{ }^{1}$ Strasbourg Univ Hospital, Strasbourg, France; ${ }^{2}$ Univ of Manchester, Centre for Musculoskeletal Research, Manchester, United Kingdom; ${ }^{3}$ Univ of Milan, Rheumatology Division, Hospital G. Pini-CTO, Milan Italy: ${ }^{4}$ Grace C Wright MD PC, New York, NY, United States of America; ${ }^{5}$ Keio Univ School of Medicine, Tokyo, Japan; ${ }^{6}$ Univ of California San Diego, Division of Rheumatology, Allergy and Immunology, La Jolla, CA, United States of America; ${ }^{7}$ Gilead Sciences, Inc, Foster City, CA, United States of America; ${ }^{8}$ Galapagos BV, Leiden, Netherlands; ${ }^{9}$ Stanford Univ, Stanford, CA, United States of America

Background: Despite effective treatments, many patients (pts) with rheumatoid arthritis (RA) have inadequate responses to biologic DMARDs (bDMARD-IR), highlighting an unmet need. It is unclear whether prior bDMARD use affects efficacy of the oral, selective JAK-1 inhibitor filgotinib (FIL).

Objectives: To explore clinical response to FIL in bDMARD-IR pts stratified by mode of action (MOA) and number of prior bDMARDs.

Methods: The global, phase 3 FINCH-2 (NCT02873936) study treated 448 bDMARD-IR pts with active RA. ${ }^{1}$ Pts were randomised 1:1:1 to once-daily FIL $200 \mathrm{mg}$, FIL $100 \mathrm{mg}$, or placebo (PBO) for 24 weeks. Efficacy was assessed by percent of pts achieving low disease activity (LDA) or remission at week (W)24 as measured by CDAl and DAS28(CRP) stratified by number and MOA of prior bDMARDs. Comparisons were not adjusted for multiplicity. Nonresponder imputation was used.

Results: In total, 448 bDMARD-IR pts were included, 105 with prior experience with $\geq 3$ bDMARDs (Table). At W24, pts receiving FIL were in LDA at a higher proportion vs $\mathrm{PBO}$, irrespective of number of prior bDMARDs or MOA (Figure 1). For pts receiving FIL 200 vs PBO, DAS28(CRP) $\leq 3.2$ was achieved at W24 by $52 \%$ vs $26 \%, 51 \%$ vs $22 \%$, and $38 \%$ vs $9 \%$ of pts with 1,2 , or $\geq 3$ prior bDMARDs, respectively, and $49 \%$ vs $21 \%$ and $50 \%$ vs $13 \%$ of pts exposed to TNF or IL-6 inhibitors; for all subgroups, rates were significantly higher vs PBO (Figure 1). Delta between FIL $200 \mathrm{mg}$ and PBO was maintained irrespective of number or type of prior bDMARDs. At W24, pts receiving FIL achieved remission at numerically higher rates vs PBO (Figure 2). For pts receiving FIL $200 \mathrm{mg}$ vs PBO, DAS28(CRP) $<2.6$ was achieved at W24 by $36 \%$ vs $14 \%, 30 \%$ vs $14 \%$, and $22 \%$ vs $6 \%$ of pts with 1,2 , and $\geq 3$ prior bDMARDs, respectively, and $31 \%$ vs $14 \%$ and $29 \%$ vs $9 \%$ of pts exposed to TNF or IL-6 inhibitors (Figure 2). Delta between FIL $200 \mathrm{mg}$ and PBO was maintained irrespective of number or type of prior bDMARDs. Treatment-emergent adverse events across subgroups were consistent with overall study population.

Table. Number and MOA of prior bDMARDs

\begin{tabular}{lcccc}
\hline & $\begin{array}{c}\text { FIL } 200 \mathbf{~ m g} \\
\mathbf{n}=\mathbf{1 4 7}\end{array}$ & $\begin{array}{c}\text { FIL } \mathbf{1 0 0} \mathbf{~ m g} \\
\mathbf{n}=\mathbf{1 5 3}\end{array}$ & $\begin{array}{c}\text { PBO } \\
\mathbf{n = 1 4 8}\end{array}$ & $\begin{array}{c}\text { Total } \\
\mathbf{N}=\mathbf{4 4 8}\end{array}$ \\
\hline Prior bDMARDs & & & & \\
$\mathbf{1}$ & $73(49.7)$ & $86(56.2)$ & $77(52.0)$ & $236(52.7)$ \\
$\mathbf{2}$ & $37(25.2)$ & $33(21.6)$ & $36(24.3)$ & $106(23.7)$ \\
$\geq \mathbf{3}$ & $37(25.2)$ & $34(22.2)$ & $34(23.0)$ & $105(23.4)$ \\
LOE $\geq \mathbf{1}$ bDMARD & $125(85.0)$ & $129(84.3)$ & $126(85.1)$ & $380(84.8)$ \\
Intolerance $\geq \mathbf{1}$ bDMARD & $36(24.5)$ & $34(22.2)$ & $32(21.6)$ & $102(22.8)$ \\
Prior TNFi & $121(82.3)$ & $134(87.6)$ & $124(83.8)$ & $379(84.6)$ \\
LOE $\geq \mathbf{1}$ TNFi & $97(66.0)$ & $113(73.9)$ & $103(69.6)$ & $313(69.9)$ \\
$\quad$ Intolerance $\geq \mathbf{1}$ TNFi & $25(17.0)$ & $24(15.7)$ & $24(16.2)$ & $73(16.3)$ \\
Prior non-TNFi & $73(49.7)$ & $62(40.5)$ & $75(50.7)$ & $210(46.9)$ \\
$\quad$ LOE $\geq \mathbf{1}$ non-TNFi & $52(35.4)$ & $43(28.1)$ & $56(37.8)$ & $151(33.7)$ \\
$\quad$ Intolerance $\geq \mathbf{1}$ non-TNFi & $13(8.8)$ & $13(8.5)$ & $11(7.4)$ & $37(8.3)$ \\
Prior IL-6i & $34(23.1)$ & $35(22.9)$ & $32(21.6)$ & $101(22.5)$ \\
$\quad$ LOE $\geq \mathbf{1}$ IL-6i & $25(17.0)$ & $22(14.4)$ & $21(14.2)$ & $68(15.2)$ \\
Intolerance $\geq \mathbf{1}$ IL-6i & $5(3.4)$ & $10(6.5)$ & $5(3.4)$ & $20(4.5)$ \\
\hline
\end{tabular}

Data presented as $\mathrm{n}(\%)$

i, inhibitor; LOE, lack of efficacy.
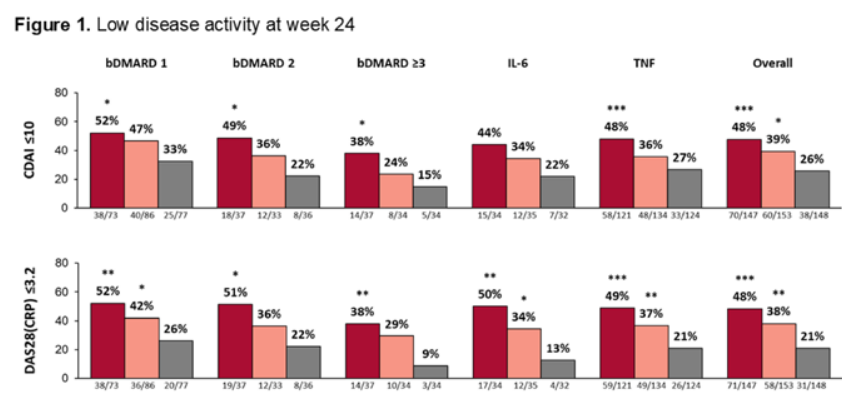

ПFLL $200 \mathrm{mg} Q \mathrm{QD} \quad \square \mathrm{FLL} 100 \mathrm{mg} \mathrm{QD} \quad \square \mathrm{PBO}$

${ }^{* * *} P<0.001$ vs $\mathrm{PBO} ;{ }^{* *} P<0.01$ vs $\mathrm{PBO} ;{ }^{*} P<0.05$ vs $\mathrm{PBO}$

bDMARD, biologic disease-modifying antirheumatic drug; CDAl, Clinical Disease Activity Index; DAS28(CRP), Disease Activity Score with C-reactive protein; FIL, filgotinib; IL, interleukin; PBO, placebo; QD, once-daily; TNF, tumour necrosis factor

Figure 2. Remission at week 24
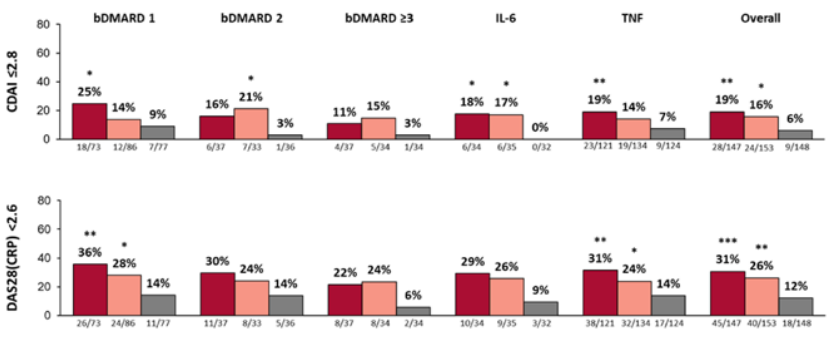

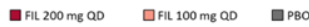

*** $P<0.001$ vs $\mathrm{PBO} ;{ }^{* *} P<0.01$ vs $\mathrm{PBO} ; * P<0.05$ vs $\mathrm{PBO}$

bDMARD, biologic disease-modifying antirheumatic drug: CDAI, Clinical Disease Activity Index DAS28(CRP), Disease Activity Score with C-reactive protein; FIL, filgotinib; IL, interleukin: PBO, placebo; QD, once-daily; TNF, tumour necrosis factor:

Conclusion: Treatment with FIL vs PBO led to higher rates of LDA and remission in pts with IR to IL-6 or TNF inhibition, or to 1,2 , or $\geq 3$ prior bDMARDs, with a similar safety profile to the overall study population. A significantly higher propor tion of pts overall receiving FIL $200 \mathrm{mg}$ vs PBO were in LDA at W24. Improved efficacy of FIL vs PBO in pts who previously failed multiple bDMARDs indicates distinct benefits of selective JAK-1 inhibition with FIL.

References:

[1] Genovese, et al. JAMA 2019;322(4):315-25.

Disclosure of Interests: : Jacques-Eric Gottenberg Grant/research support from: BMS, Pfizer, Consultant of: BMS, Sanofi-Genzyme, UCB, Speakers bureau: Abbvie, Eli Lilly and Co., Roche, Sanofi-Genzyme, UCB, Maya H Buch Grant/research support from: Pfizer, Roche, and UCB, Consultant of Pfizer; AbbVie; Eli Lilly; Gilead Sciences, Inc.; Merck-Serono; Sandoz; and Sanofi, Roberto Caporali Consultant of: AbbVie; Gilead Sciences, Inc.; Lilly; Merck Sharp \& Dohme; Celgene; Bristol-Myers Squibb; Pfizer; UCB, Speakers bureau: Abbvie; Bristol-Myers Squibb; Celgene; Lilly; Gilead Sciences, Inc; MSD; Pfizer; Roche; UCB, Grace C. Wright Consultant of: AbbVie Amgen, Bristol-Myers Squibb, Exagen, Eli Lilly, Myriad Autoimmune, Novartis, Pfizer, Regeneron Pharmaceuticals, Inc., Sanofi Genzyme, UCB, Speakers bureau: AbbVie, Amgen, Bristol-Myers Squibb, Exagen, Eli Lilly, Myriad Autoimmune, Novartis, Regeneron Pharmaceuticals, Inc., Sanofi Genzyme, UCB, Tsutomu Takeuchi Grant/research support from: Eisai Co., Ltd, Astellas Pharma Inc., AbbVie GK, Asahi Kasei Pharma Corporation, Nippon Kayaku Co., Ltd, Takeda Pharmaceutical Company Ltd, UCB Pharma, Shionogi \& Co., Ltd., Mitsubishi-Tanabe Pharma Corp., Daiichi Sankyo Co., Ltd. Chugai Pharmaceutical Co. Ltd., Consultant of: Chugai Pharmaceutical Co Ltd, Astellas Pharma Inc., Eli Lilly Japan KK, Speakers bureau: AbbVie GK, Eisai Co., Ltd, Mitsubishi-Tanabe Pharma Corporation, Chugai Pharmaceutical Co Ltd, Bristol-Myers Squibb Company, AYUMI Pharmaceutica Corp., Eisai Co., Ltd, Daiichi Sankyo Co., Ltd., Gilead Sciences, Inc., Novartis Pharma K.K., Pfizer Japan Inc., Sanofi K.K., Dainippon Sumitomo Co. Ltd., Kenneth Kalunian Grant/research support from: Pfizer, Lupus Research Alliance, Sanford Consortium, Consultant of: Genentech, Nektar, BMS Janssen, AstraZeneca, Biogen, Vielabio, Equillium, Eli Lilly, ILTOO, Abbvie Amgen, Roche, Gilead, Alena Pechonkina Shareholder of: Gilead Sciences, Inc., Employee of: Gilead Sciences, Inc., Ying Guo Shareholder of: Gilead Sciences, Inc., Employee of: Gilead Sciences, Inc., Shangbang Rao Shareholder of: Gilead Sciences Inc., Employee of: Gilead Sciences Inc., YingMeei Tan Shareholder of: Gilead Sciences, Inc., Employee of: Gilead Sciences, Inc., Robin Besuyen Shareholder of: Galapagos, Employee of: Galapagos, 
Mark C. Genovese Grant/research support from: Abbvie, Eli Lilly and Company, EMD Merck Serono, Galapagos, Genentech/Roche, Gilead Sciences, Inc., GSK, Novartis, Pfizer Inc., RPharm, Sanofi Genzyme, Consultant of: Abbvie, Eli Lilly and Company, EMD Merck Serono, Genentech/Roche, Gilead Sciences, Inc., GSK, Novartis, RPharm, Sanofi Genzyme DOI: 10.1136/annrheumdis-2020-eular.2237

\begin{tabular}{|l|l}
\hline THU0205 & RESPONSE TO SMALL MOLECULES IS MOSTLY \\
DRIVEN BY PATIENT GLOBAL ASSESSMENT OF \\
DISEASE: A REAL WORLD OBSERVATION
\end{tabular}

C. Joseph ${ }^{1}$, S. M. Bilgrami ${ }^{2}$, L. Ottewell ${ }^{2}$, L. Gray ${ }^{2}$, W. Mitchell ${ }^{2}$, F. Wood ${ }^{2}$, M. Massarotti ${ }^{2}$, M. Bukhari ${ }^{1,2},{ }^{1}$ Lancaster Univeristy, Lancaster, United Kingdom; ${ }^{2}$ University Hospitals of Morecambe Bay NHS Foundation Trust, Lancaster, United Kingdom

Background: Two Small molecules (Tofacitinib and Baricitinib) have been licensed in the UK for the use in rheumatoid arthritis. Their licensing came from several studies that showed good efficacy with baricitinib (1) study showing superior efficacy to adalimumab and tofacitinib showing non inferiority to TNF drugs (2). The response has also been shown in patient reported outcomes (find reference). Response when measure using the DAS score has two relatively subjective components (tender joints and patient global assessment) and two relatively objective components (Swollen joints and inflammatory markers)

Objectives: To determine in a real world setting if the response to small molecules is mostly due to a drop in subjective or objective components of the DAS score

Methods: A retrospective chart review was done on all new starters on small molecules in a district hospital in the North of England. Data were collected at baseline, three months and six months from October 2018 to date. Drop in the components of the DAS28 score was calculated and overall drop in DAS28 was modelled as the explanatory variable using linear regression modelling. This was the done Adjusting for age gender and duration of disease. Sensitivity of the model was examined using a logistic model of EULAR moderate/good response and using adjusted $R$ squared estimates for linear model of improvement of the DAS28 score.

Results: 76 patients were included in the analysis from 85 starters on small molecules.61 $(71.8 \%)$ were on baricitinib and the baseline median DAS28 score was .5.97 (IQR 5.35,6.55)The median drop at three months in the DAS28 score was 2.42 (IQR 1.33,3.31). and at six months was 2.77 (IQR $2.01,3.83)$. There was numerical relative increased efficacy of baricitinib but this was not statistically significant (DAS drop at three months 2.54 IQR $1.73,3.09$ vs 2.12 IQR $1.51,3.5$ ). The relative contribution of the individual components of the DAS score to the drop ae in DAS are shown in table 1 below. Sensitivity analysis looking at predictors of a DAS drop of $>0.6$ confirmed this finding.

Table 1. Results of the adjusted linear regression models.

Component of DAS dropping at three Adjusted R squared at 3 months Adjusted R squared months

at six months

\begin{tabular}{lll}
\hline Swollen Joints & 0.12 & 0.05 \\
Tender Joints & 0.28 & 0.18 \\
Patient global assessment & 0.31 & 0.48 \\
Erythrocyte sedimentation rate & 0.04 & 0.17
\end{tabular}

Conclusion: In this real world observational study, there was a good response to both small molecules with numerical better response to baricitinib. Tender joint count and patient global response accounted for more of the drop in DAS28 than swollen joints and inflammatory markers. At six months the biggest contributor to response was patient global assessment. This shows that JAK inhibitors might mediate their response initially mostly through pain modulation then by inflammation as exposure to drug continues.

References:

[1] N Engl J Med. 2017 Feb 16;376(7):652-662

[2] N Engl J Med. 2014 Jun 19;370(25):2377-86

Disclosure of Interests: : Clerin Joseph: None declared, Syed Mujtaba Bilgrami Speakers bureau: Pfizer, Lesley Ottewell: None declared, Leanne Gray: None declared, William Mitchell: None declared, Fiona Wood: None declared, Marco Massarotti: None declared, Marwan Bukhari Speakers bureau: Bristol-Myers Squib, UCB celltech, Roche/Chugai, Pfizer, Abbvie, Merck, Mennarini, Sanofiaventis, Eli-Lilly, Janssen, Amgen and Novartis.

DOI: 10.1136/annrheumdis-2020-eular.3118

\section{THU0206 \\ A VERY EARLY (7-28 DAYS) RESPONSE ON JAK INHIBITOR TOFACITINIB IN PATIENTS WITH ACTIVE RHEUMATOID ARTHRITIS: EFFECT ON PAIN AND CENTRAL SENSITIZATION.}

A. Karateev ${ }^{1}$, E. Filatova ${ }^{1}$, E. Pogozheva ${ }^{1}$, V. Amirdzhanova ${ }^{1}$, E. Nasonov ${ }^{1}$,

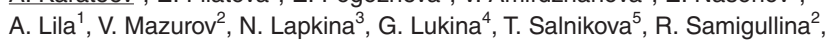
D. Chakieva ${ }^{2}$, I. Marusenko ${ }^{6}$, O. Semagina ${ }^{7}$, M. Semchenkova ${ }^{8} .{ }^{1}$ Nasonova Research Institute of Rheumatology, Moscow, Russian Federation; ${ }^{2}$ Mechnikov North-Western State Medical University, St-Petersburg, Russian Federation ${ }^{3}$ Yaroslavl State Medical University, Yaroslavl, Russian Federation; ${ }^{4}$ Moscow Clinical Scientific and Practical Centre named after Loginov AS, Moscow, Russian Federation; ${ }^{5}$ Regional Clinical Hospital, Tula, Tula, Russian Federation; ${ }^{6}$ Petrozavodsk State University, Petrozavodsk, Russian Federation; ${ }^{7}$ Regional Clinical Hospital, Samara, Samara, Russian Federation; ${ }^{8}$ Smolensk State Medical University, Smolensk, Russian Federation

Background: The presence of central sensitization (CS) significantly burdens the course of rheumatoid arthritis (RA). JAK inhibitors block intracellular signal pathways including the ones responsible for synthesis of mediators and cytokines causing pain and CS. The application of JAK inhibitors is supposed to relieve pain and reduce CS severity promptly.

Objectives: To evaluate JAK inhibitor effect on pain and signs of CS in patients with active RA 7 and 28 days after the start of therapy.

Methods: Study group included 39 patients with RA, their age was $50.9 \pm 11.1$, $79.5 \%$ of women, $89.7 \%$ of RF "+", DAS28 $5.8 \pm 0.6$, receiving DMARDs (methotrexate $82.0 \%$ and leflunomide $18.0 \%$ ), who were administered with tofacitinib $5 \mathrm{mg} 2$ times a day due to inefficiency or intolerance of genetically engineered biological drugs. There were assessed the pain severity using Brief pain inventory (BPI) questionnaire, the presence of neuropathic pain component (NPC) using PainDETECT questionnaire and signs of CS using Central Sensitisation Inventory (CSI) questionnaire at early time after tofacitinib administration.

Results: Patients initially experienced a severe pain $-5.72 \pm 2.21$ according to the visual analogue scale (VAS), $53.8 \%$ had signs of central sensitization (CSI $\geq 40$ ), $17.9 \%$ had NPC (PainDETECT $\geq 18$ ). 7 days after tofacitinib intake there was statistically reliable reduction of pain severity - up to $4.37 \pm 2.2(p=0.01)$, pain decrease of $29.4 \pm 17.9 \%$ (BPI), NCP - PainDETECT from $12.9 \pm 5.5$ to $10.6 \pm 5.6 \quad(p=0.047)$ and CS $-C S I$ from $43.1 \pm 12.8$ to $35.9 \pm 11.2(p=0.01)$. The effect had increased after 28 days: pain level (VAS) was $2.84 \pm 1.57(p=0.000)$, pain decrease of $43.6 \pm 29.6 \%$ (BPI), PainDETECT 29.8 $\pm 12.4(p=0.000), C S I 26.4 \pm 13.9(p=0.000)$.

During this period there were no serious adverse reactions.

Conclusion: The application of JAK inhibitor tofacitinib allows to reach a fast analgesic effect, also due to impact on CS and NCP.

Source: National Registry patients with RA

Disclosure of Interests: : Andrey Karateev: None declared, Ekaterina Filatova: None declared, Elena Pogozheva: None declared, Vera Amirdzhanova: None declared, Evgeny Nasonov: None declared, Alexander Lila: None declared, V Mazurov: None declared, N Lapkina: None declared, Galina Lukina Speakers bureau: Novartis, Pfizer, UCB, Abbvie, Biocad, MSD, Roche, Tatiana Salnikova: None declared, Ruzana Samigullina: None declared, Diana Chakieva: None declared, Irina Marusenko: None declared, Olga Semagina: None declared, Marina Semchenkova: None declared DOI: 10.1136/annrheumdis-2020-eular.4029

\section{THU0207 \\ SUSTAINABILITY OF RESPONSE TO UPADACITINIB AS MONOTHERAPY OR IN COMBINATION AMONG PATIENTS WITH RHEUMATOID ARTHRITIS AND PRIOR INADEQUATE RESPONSE TO CONVENTIONAL SYNTHETIC DMARDS}

A. Kavanaugh ${ }^{1}$, M. H. Buch ${ }^{2}$, B. Combe ${ }^{3}$, L. Bessette ${ }^{4}$, I. H. Song ${ }^{5}$, Y. Song ${ }^{5}$, J. Suboticki ${ }^{5}$, P. Nash ${ }^{6} .{ }^{1}$ University of California San Diego, San Diego, United States of America; ${ }^{2}$ University of Manchester \& NIHR Manchester Biomedical Research Centre, Manchester, United Kingdom; ${ }^{3}$ Lapeyronie Hospital, Montpellier University, Montpellier, France; ${ }^{4}$ Université Laval, Centre Hospitalier de l'Université Laval, Quebec, Canada; ${ }^{5}$ AbbVie Inc., North Chicago, United States of America; ${ }^{6}$ School of Medicine, Griffith University, Brisbane, Australia

Background: The primary treatment goal for patients (pts) with rheumatoid arthritis (RA) is a state of sustained clinical remission (REM) or low disease activity (LDA). ${ }^{1,2}$

Objectives: To assess the long-term sustainability of responses to upadacitinib (UPA), a JAK inhibitor, with or without background csDMARD(s) in pts with RA. Methods: Data are from two phase 3 randomized, controlled trials of UPA in RA pts with roughly similar baseline disease characteristics: SELECT-NEXT enrolled pts with an inadequate response (IR) to $\operatorname{csDMARD}(\mathrm{s})$ on background stable csDMARD(s) receiving UPA $15 \mathrm{mg}$ or $30 \mathrm{mg}$ once daily or placebo for 12 weeks (wks); 